\title{
Postbiotics as Dynamic Biological Molecules for Antimicrobial Activity: A Mini-Review
}

\author{
Aziz Homayouni Rad ${ }^{1}$ (D), Samira Hosseini ${ }^{2, *}$, Hadi Pourjafar ${ }^{3,4, *(D)}$ \\ 1 Department of Food Science and Technology, Faculty of Nutrition and Food Sciences, Tabriz University of Medical \\ Sciences, Tabriz, Iran; homayounia@tbzmed.ac.ir (A.H); \\ 2 M.se Student of Food Hygiene and Safety, Faculty of Nutrition and Food Sciences, Tabriz University of Medical Science, \\ Tabriz, Iran; samira.hosseini575@gmail.com (S.H); \\ 3 Alborz University of Medical Sciences, Dietary Supplements and Probiotic Research Center, Karaj, Iran, \\ pourjafarhadi59@gmail.com (H.P); \\ 4 Department of Food Sciences and Nutrition, Maragheh University of Medical Sciences, Maragheh, Iran \\ * Correspondence: pourjafarhadi59@gmail.com (H.P); and samira.hosseini575@gmail.com (S.H);
}

Scopus Author ID 54881252100

Received: 12.06.2021; Revised: 19.09.2021; Accepted: 22.09.2021; Published: 19.11.2021

\begin{abstract}
Postbiotics, products, or metabolites secreted by living probiotic bacteria like teichoic acids, peptides, enzymes, peptidoglycans, polysaccharides, organic acids, and external cell proteins are said to be produced during the bacterial fermentation process. However, postbiotics may provide immunization, antioxidant, prevents inflammation, low cholesterolemic, antimicrobial, antagonistic obesity, contrast hypertensive, and diabetic retinopathy impacts. In the current review, we attempt to display the antimicrobial performance of postbiotics. In this regard, we considered microbial strains used as postbiotic sources and postbiotics as antimicrobial agents in food products. All databases such as Science Direct, Scopus, Pub Med, and Google Scholar were examined using the following keywords: "postbiotics", "Antimicrobial activity", "Anti-inflammatory", and "Low cholesterolemic". Further studies demonstrated that probiotics are fed special forms of fiber (prebiotic) molecules, indicating substances known as postbiotics. Furthermore, short-chain fatty acids (SCFAs) like acetate, propionate, and butyrate are among the comprehensively investigated postbiotics. The extraction and purification of these compounds are carried out by means of dialysis, centrifugation, and freeze-drying techniques. According to the gained results, postbiotics assist in improving host health by increasing certain physiological functions. Furthermore, postbiotics can be used to increment the useful lifetime of different foods, like dairy products. It has also been shown that manually adding postbiotics to such products prevents the growth and proliferation of molds and thus the spoilage caused by them. This inhibitory effect indicates the antimicrobial properties of these compounds. Finally, we will see significant advances in the biological preservation of products, especially in the food industry.
\end{abstract}

Keywords: postbiotics; antimicrobial activity; anti-inflammatory; prebiotic; low cholesterolemic; food industry.

(C) 2021by the authors. This article is an open-access article distributed under the terms and conditions of the Creative Commons Attribution (CC BY) license (https://creativecommons.org/licenses/by/4.0/).

\section{Introduction}

Since postbiotics have been discovered late and investigation has not developed, thus, access to probiotics is not easy. If you seek postbiotic supplements, choose elements that include distinctive kinds of postbiotic, mainly short-chain fatty acids [1], which can be used as a substitute for some nutrients in diets. The human gut is home to many microbiotas, and postbiotic compounds can effectively maintain the balance of this microbiota [2]. 
Probiotics are beneficial microorganisms that have one or more health effects on the consumer. Most of these health effects can be caused by the production of postbiotics by probiotics in the food product or the host body. However, the molecular mechanisms of probiotic function are complex and remain largely unknown [3]. In addition, despite the protected role of probiotics in the gut, there are problems with uncertainty about bioavailability, risk of infection, and the possibility of antibiotic resistance gene transfer [4]. One of the important goals in maximizing the beneficial effects of probiotics is to increase their survival rate within the fermented products and while passing through the host gastrointestinal tract to reach the main place of activity, the colon, in acceptable numbers $\left(10^{7} \mathrm{cfu} / \mathrm{g}\right.$ or $\left.\mathrm{ml}\right)$. Probiotics can help keep up stomach-related well-being by controlling destructive microscopic organisms' development and bolsters prebiotics amid a fermentation process, which could be a by-product of postbiotics [5]. Researchers have shown that postbiotics may support forestall total diabetes in individuals with pre-diabetes [6]. Once microbiota is parenthetically out of balance, making affront resistance or pre-diabetes within the person is conceivable [7].

It has been shown that a specific postbiotic named Muramyl Dipeptide (MDP) could diminish affront resistance notwithstanding conditions such as weight misfortune or changes within the intestine microbiome amid corpulence [8]. Schertzer concluded that the imbalance of microbiota and consequently the disruption in the production of postbiotics have a significant effect on the development of diabetes [9]. Therefore, it should be borne in mind that the reduction and imbalance in the number and types of natural microorganisms in the gastrointestinal tract can play a role in developing type 2 diabetes [10]. It is now clear how the gut microbiota sends signals to lower blood sugar [11]. Karim et al. (2017) inspected Effects from the distinctive composition of postbiotics and inulin RG14 upon development execution, cecal smaller scale biota, unstable greasy volatile fatty acids, and perfect cytokine explanation at Broilers [12].

The discoveries of inquiring about seem that the appearance of Interleukin 8/Chemokine (C-X-C motif) value was not affected with slim down. Inulin (as a prebiotic) and postbiotics (originated from probiotics)mixture are possible replacements to antimicrobial development boosters within the aviculture industry [13]. Konstantinos et al. [14] summarized a part from postbiotics at keeping up colonic's well-being then offered that postbiotics can stand a more secure elective at the analogy to living microbes. Studies have shown that the use of probiotics that produce post-antibiotics such as exopolysaccharides can contribute to gastrointestinal health and prevent diseases such as colon and rectal cancer [15] as Tsilengiri et al. suggested usage from postbiotic within therapy and anticipation with gut-relevant illnesses like provocative intestine illness [16].

In 2017, an effective audit was distributed, which checked on randomized, controlled human considers with any clinical endpoint where the mediation was a slaughtered probiotic [17]. Forty ponders were included within the audit. These 40 thinks were heterogeneous with respect to endpoint (avoidance or treatment of a cluster of infections), organism, ponder populace (grown-ups or pediatric). Creators point out, even though that thinks about were likely not fueled to identify a contrast. In two treatment thinks, slaughtered probiotics were way better than live [18]. In one avoidance consider, life was way better than murder. The audit, too, looked for proof of antagonistic impacts of the slaughtered organisms. Tragically, as is regularly the case, most ponders did a destitute work of collecting or detailing antagonistic events so that no conclusion can be made [19]. 


\section{Postbiotics}

Postbiotics are useful bioactive complexes produced in a milieu throughout the fermentation process, which can be employed to promote the healthiness of consumers. The more prebiotic carbohydrates available to probiotics, the more diverse postbiotics are produced in the fermentation environment [20]. Some studies have shown that in some cases, probiotics themselves can not play a role in maintaining and promoting intestinal health, but the postbiotics they produce can play an effective role in this regard [21]. Different types of postbiotics, including muramyl dipeptide, teichoic acid, lipopolysaccharide, exopolysaccharides, lactospin, and indole, are produced by probiotics. Short-chain fatty acids, such as acetic acid, butyric acid, and propionic acid, are among the leading largely scrutinized postbiotics [22]. These fatty acids play a major role in the physiological and digestive functions of the intestines. Participating in specific metabolic pathways and digestion and absorption of food play an important role in maintaining intestinal health [23]. Short-chain carbohydrates as probiotic postbiotics are not affected via human stomach-related proteins and advance has wellbeing by invigorating the development or action of one or a number of intestine microbiota [23-24]. These compounds originated from Lactobacillus species play their antimicrobial role in food and the host body as a substitute for live probiotic cells without an adequate number of probiotics [18]. Postbiotic may be a metabolic by-product created by a probiotic microorganism that impacts the host's organic capacities [25].
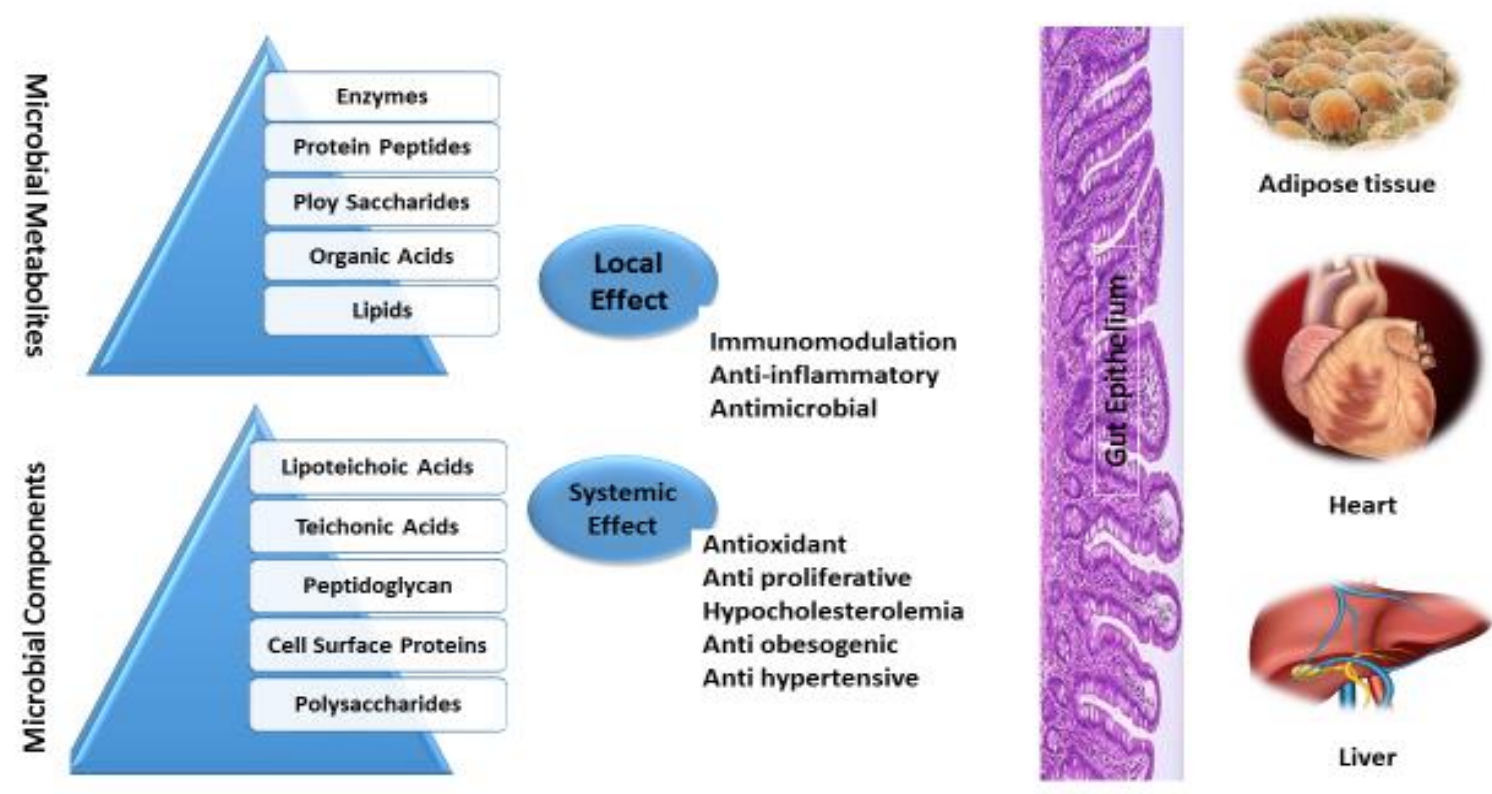

Antioxidant Anti proliferative ocholesterolemia Anti obesogeni Anti hypertensive

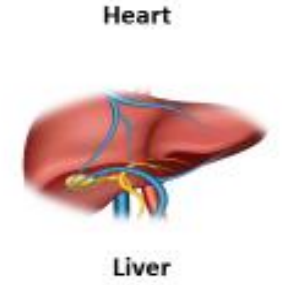

Figure 1. Applications of postbiotics and their potential local.

Bacterial by-products, determined as postbiotics, offer assistance in lowering blood sugar levels in stout individuals with pre-diabetes [26]. Scientists believe that postbiotics can assist overweight individuals with pre-diabetes and prevent them from creating type 2 diabetes [26-27]. Recently, postbiotics have been considered useful prebiotics that, in addition to having beneficial effects on their own, as a rich source of carbohydrates, nourish and increase the effectiveness of probiotics [28]. With the production of postbiotics, especially short-chain fatty acids, the $\mathrm{pH}$ is reduced, and the conditions for the growth and activity of pathogenic bacteria are limited [29]. 
Postbiotics are important for stimulating the growth and activity of Bifidobacterium and Lactobacillus bacteria [30]. Previously, the presence and activity of bacteria were thought to increase inflammatory reactions and increase blood sugar. Still, today it has been proven that the presence of probiotic bacteria and postbiotic compounds reduces blood sugar and improves insulin function in obese people [31]. In an investigation that researchers were bred to manipulate obese mice genetically, it was found that postbiotics increase the effect of insulin [32-35].

\section{Antimicrobial Activity of Postbiotics}

Postbiotics have emerged to address the potential bacterial hazards of living cell probiotics, based on the idea that bacterial survival is not essential for human health [36]. Although the postbiotics investigation is still generally later, antimicrobial properties show up to be one of their benefits [37]. Studies have shown that postbiotic compounds have antibacterial (pathogenic and spoiler bacteria) effects, thus preventing infectious diseases and food spoilage. These compounds prevent the colonization of pathogenic bacteria in the intestine and prevent intestinal diseases such as bad-tempered bowel disorder or provocative bowel illness [38]. Postbiotics are unmistakable living beings that apply advantageous impacts on the well-being of the have by influencing the microbial greenery of the body and preventing the replacement of invading bacteria in the gut wall, the production of antimicrobial agents, and changes in environmental acidity [39]. Therefore, by maintaining the balance of intestinal microbiota and establishing the process of fermentation and production of post-antibiotics, the rate of intestinal infections and even other diseases related to the gastrointestinal tract is significantly reduced $[40,41]$. By binding to bacterial receptors, postbiotics do not permit pathogenic microorganisms such as toxin-producing Clostridia, and E. coli and eliminate them from the bowel lumen $[42,43]$.

Recent development in the understanding of postbiotics natural effects and relevant components uncovered it postbiotics are a proposing compelling prophylactic methodology to anticipate the chance of keeping up alive microorganisms or preterm newborn children that might replace and lead to disease [44, 45].

\section{Microbial Strains Used as Postbiotic Sources}

This can be required utilizing the need to avoid the improvement of safe antimicrobial strains of microbes that will propose at warm to human well-being [46]. Lactobacillus strains connected in people have to be utilized as postbiotics in creatures; in any case, Bifidobacterium strains segregated of a human source were utilized as postbiotics in people [47]. Over the last few decades, in most countries, including Europe, Bacillus strains are mainly used to produce postbiotics [48]. The main products of postbiotics are related to the production of different types of these compounds in the laboratory, such as the production of short-chain volatile fatty acids and exopolysaccharides. Also, most of the postbiotics employed in living being cultivating are lab resources of these compounds to apply at several animal species of aviculture [49], the pig [50], and likewise ruminants [51]. These compounds may additionally be separated from diverse feces species of animals, such as chicks [52], pig [53], and ruminants [54, 55]. Bacillus pumilus Mind 588 separated from ocean water have been inspected at creatures and appear plausibly for developing E. coli [56]. 
Giang et al. have separated lactic acid bacteria (LAB) from different materials areas of insides in sound stuffing pigs. These bacterial strains comprised Enterococcus faecium, L. acidophilus, L. plantarum, and Pediococcus pentosaceus and were utilized like postbiotics sources of weaned piglets to extend the development [56-57]. LAB strains such as Pediococcus pentosaceus, P. lolii, L. pentosus, L. plantarum, L. buchneri, L. rapi, and L. rhamnosus have been isolated from silages of humid and hot environments $[58,59]$. Some studies have shown that LAB separated from youthful fecal calves such as L. johnsonii, L. salivarius, and $L$. murinus, have a capacity for form such as bacteriocin action versus pathogens [60].

A few inquires have detailed the postbiotics strains, Separate from both new Aquatic and ocean Aquatic creatures [61]. Detailed that L. salivarius from bottlenose porpoise can hinder the development of Salmonella enteritidis strains that separated both maritime creatures and people [62]. Detailed Lactobacillus strains were isolated from the little guts of piglets; most of the strains were of the L. salivarius species [63]. These strains appeared hopeful postbiotics virtues, comprising resistor to a $\mathrm{pH}$ of 3 and, auto-aggregation impacts and a capacity to appear the pathogen E. coli K88 emphatically [64].

Leuconostoc mesenteroides is a species of LAB separated from the bowel of freshwater fishes like snakehead fish [53] and Nile tilapia fish [65]. Employed postbiotics originated from Leuconostoc cremoris and Weissella cibaria of Atlantic salmon fish and possessed common octopuses [66].

Sarkono et al. have shown that L. paracasei separated from Normal state have a resistor to bile and acidic situation and have antibacterial activity against some pathogenic bacteria such as Bacillus cereus, Staphylococcus aureus, and E. coli [67].

Leuconostoc mesenteroides strains have been separated from the guts by new water angles like snakehead fish angle [68] and Nile tilapia angle [69-71].

Table 1. Some bacterial activities species of postbiotics.

\begin{tabular}{lc} 
Competition with pathogen & References \\
\hline Lactobacillus plantarum I-UL4 & {$[61]$} \\
\hline Lactobacillus rhamnosus & {$[66]$} \\
\hline Lactobacillus paracasei & {$[68]$} \\
\hline Faecalibacterium prausnitzii & {$[68]$} \\
\hline Lactobacillus brevis & {$[70]$} \\
\hline Lactobacillus pentosus & {$[70]$} \\
\hline Lactobacillus gasser & {$[71]$}
\end{tabular}

\section{Postbiotics as Antimicrobial Agents in Food Products}

LAB are completely affirmed as secure, dynamic, and utilitarian fixings for nourishments have a place in their long foundation of utilization along with aged nourishments [72]. Additionally, their metabolic conclusion items, like lactic acid and bacteriocin, can be utilized like normal perspective and antimicrobial operators against nourishment deterioration and defilement [73].

Beneficial effects of LAB have been determined exactly, for example, the prevention from urogenital infections [74], control from inflammatory intestine diseases [75], immunomodulation action [76], control of serum cholesterol [77], and hamper specific kinds of cancer [78]. Cell-free supernatant from L. plantarum YML 007 having a bio-preserving impact on soybeans caused enhanced shelf life of unshelled soybeans up to 2 months [79]. Exopolysaccharide from L. rhamnosus showed an $8.2 \%$ increase in Cheddar cheese yield with 
L. lactis [68]. Bifidin from Bifidobacterium lactis $\mathrm{Bb}-12$ resulted in increasing the shelf life of minced meat up to 3 months at $-18^{\circ} \mathrm{C}$ by $100 \%$ reduction of E. coli O157:H7 [80].

Numerous components intervening in the well-being benefits of advantageous bacterial cells do vital practicality [81]. In any case, unused terms like postbiotic or paraprobiotic have developed to indicate that dead microbial cells, microbial divisions, or cell lysates are possible to propose physiological preferences for making extra bioactivity [82]. Postbiotics derived from LAB have been extensively studied, and it has been proven that each specific genus and species of this family produce specific postbiotics that have the property of dissolving. Also, the colonies of these bacteria are mucoid form in the culture medium and, in many cases, produce a film [83]. L. plantarum, as a primary strain of LAB can make PM with unmistakable postbiotics impacts detailed [84]. In addition to the developing reports of anticancer highlights of $\mathrm{LAB}$, much-districted knowledge is available on the anti-proliferative and cytotoxic activity of PM produced via L. plantarum. Consequently, the cytotoxicity from PM discharged via 6 strains of $L$. plantarum on various cancer and normal cells has been explored [85].

Lb. plantarum YML 007

preservative effect on soybeans resulted
in improved shel life

Lb. rhamnosus

showed $8.2 \%$ increase in Cheddar cheese
yield with L.lactis

Bifidobacterium lactic Bb-12

\section{increasing Shelf life of minced meat up to 3} months

Figure 2. Postbiotic pathogens in the food industry.

\section{Antimicrobial mechanisms of postbiotics}

The potential utilization of postbiotic metabolites as a replacement for in-feed antimicrobials in animals has been inspected and demonstrated to be valuable [86]. Postbiotics propose to imitate the viable restorative impacts, anticipating the hazard of keeping up live microorganisms to preterm newborn children with youthful intestinal boundaries or disabled resistant protections [87]. Inside the gastrointestinal tract, many microorganisms can catabolize indigestible carbohydrates to produce large amounts of butyrate and volatile short-chain fatty acids [89].

Here are some of the health-promoting effects of postbiotics:

Impact on constipation: Existence and incomplete fermentation of carbohydrates in the gastrointestinal tract causes water to be trapped inside and, as a result, causes constipation. Also, fermentation of fibrous food products in the colon enhances microbiota capacity and amount of stool [90]. In a study of the elderly, it was shown that feeding on inulin (as an indigestible carbohydrate/prebiotic) relieves constipation and increases the amount of feces [91]. Postbiotics such as exopolysaccharides, which have a carbohydrate structure, have similar effects. 
Impact on blood lipid-lowering: Studies have shown that postbiotics reduce the amount of lipids in the blood of animals. However, confirmation of this effect on humans requires further studies [92]. It has also been shown that postbiotics affect the activity of triglycerides and reduce the synthesis of fatty acids, which again has not been proven in humans [93].

Impact on inflammatory diseases: Postbiotics can strengthen the immune system of the body and the immune system of the gastrointestinal tract by strengthening and changing the flora of the intestinal tract, and as a result, prevent the occurrence of inflammatory diseases, especially intestinal inflammation [94].

Impact on the absorption of beneficial elements: investigations conducted on animal and human models have shown the helpful activity of postbiotics in the uptake of calcium, magnesium, zinc, and iron elements [95]. Human studies have indicated that digestible oligosaccharides positively affect calcium absorption when needed, especially during puberty and menstruation. Enhancing the amount of calcium, potassium, and magnesium ions in the intestinal lumen controls and prevents cellular transformation [96].

Impact on cancer lessening: Studies have shown that with an increasing amount of probiotics in the gastrointestinal tract, the production of postbiotics such as oligosaccharides and butyrate is increasing that these compounds play an important role in controlling preventing cell deformation and cancer [97]. Also, it has been shown that postbiotics can increase the activity of Lactobacillus and Bifidobacteria, causing these bacteria to join with certain carcinogens and neutralizing them [98]. Indeed, the ideal generation of inhibitory action of postbiotic highlights is crucial, agreeing to its improving mechanical capacities. Consider in past decades has highlighted the improvement of bacitracin generation beneath controlled aging circumstances [99].

\section{Future Perspectives of Postbiotics}

This article reviews the antimicrobial properties of postbiotics and highlights aspects of overcoming microbial resistance. With enhancing impacts of antibiotics, it gives the impression that co-administration of antibiotics and postbiotics can be a proper way to overwhelm the problem of microbial resistance. However, proof of this theory requires extensive laboratory and clinical animal and human studies [100,101]. The most refinement between a postbiotic and a probiotic is that a probiotic must be an alive organism when managed [102]. Postbiotics refer to different parts of a dead and broken cell or to the extracellular secretions of living bacteria. The most intrigued in postbiotics stems from the viable reality that after you don't get to stress approximately keeping the organism lively, fabricate, bundling, capacity, transport, and all taking care of for all intents and purposes are enormously simplified. Because of its activity, the structure of a probiotic may raise concerns about a possible infection; inactive and dead organisms are a safer alternative to probiotics. Already, a series of studies are proving the effects of post-biotics on human health. One of the applications to increase the effectiveness of postbiotics can be microencapsulation of these compounds, as probiotics are microencapsulated to increase the viability and targeted release $[103,104]$. 


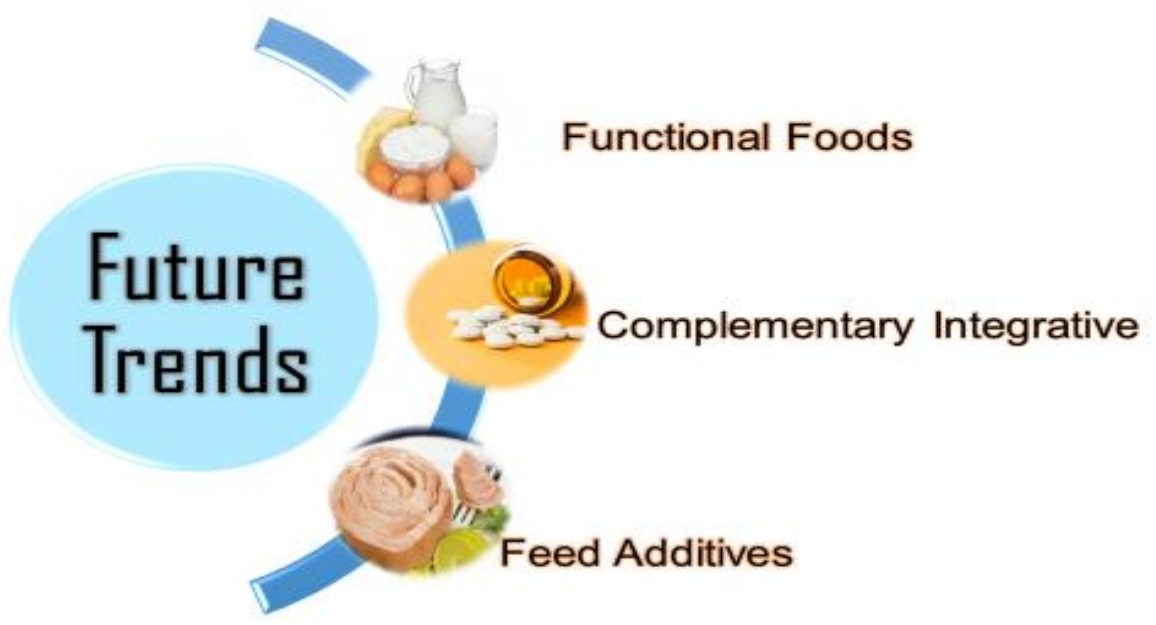

Figure 3. Future trends of postbiotic applications.

\section{Conclusions}

Nowadays, there is increasing attention to probiotic impacts determined using microbial metabolites considered like bioactive postbiotic metabolites. Postbiotics are considered dissolvable agents (items or metabolic by-products), created using live microorganisms, or discharged then bacterial lysis, like as proteins, teichoic acids, peptides peptidoglycan is taken peptidoglycans, cell surface proteins, polysaccharides, and natural acids. These postbiotic have fallen intrigued according to their self-evident chemical features, security dosage items, long rack life, and the substance of diverse signaling particles that will have anti (inflammatory obesogenic, immunomodulatory, hypertensive, proliferative, oxidant) hypocholesterolemia applications. These focused favors which postbiotics may chip into the advancement of having well-being with raising certain physiological needs implementation, in spite of the fact that the proper items have not been completely clarified.

\section{Funding}

This study was financially supported by grants from Tabriz University of Medical Sciences.

\section{Acknowledgments}

The authors would like to express their thanks to the Research vice-chancellor of Tabriz University of Medical Sciences for financial support of this study.

\section{Conflicts of Interest}

The authors declare no conflict of interest.

\section{References}

1. Usha, G.; Ravi, D.; Parthasarathy, R. Synthesis of Bacteriocin by Synbiotic Effect and Its Antibacterial Activity againstSelected Respiratory tract Pathogens. Int $J$ Adv Res 2013, 1, 296-303, http://www.journalijar.com/article/644/.

2. Rossoni, R.D.; de Barros, P.P.; do Carmo Mendonça, I.; Medina, R.P.; Silva, D.H.S.; Fuchs, B.B.; Junqueira, J.C.; Mylonakis, E. The postbiotic activity of Lactobacillus paracasei 28.4 against Candida auris. Front Cell Infect Microbil 2020, 10, 397, https://doi.org/10.3389/fcimb.2020.00397.

3. Goudarzi, L.; Kasra Kermanshahi, R. The Effect of Prebiotics on Production of Antimicrobial Compounds from Lactobacillus spp. Against Proteus mirabilis (ATCC 7002 and PTCC 1076). Iran Food Sci Technol Res $J$ 2015, 11, 41-47. www.sid.ir/en/journal/ViewPaper.aspx?id=535997. 
4. Bindels, L.B.; Delzenne, N.M.; Cani, P.D.; Walter, J. Towards a more comprehensive concept for prebiotics. Nat. Rev. Gastroenterol. Hepatol. 2015, 12, 303-310, https://doi.org/10.1038/nrgastro.2015.47.

5. Izuddin, W.I.; Humam, A.M.; Loh, T.C.; Foo, H.L.; Samsudin, A.A. Dietary Postbiotic Lactobacillus plantarum Improves Serum and Ruminal Antioxidant Activity and Upregulates Hepatic Antioxidant Enzymes and Ruminal Barrier Function in Post-Weaning Lambs. Antioxidants 2020, 9, 250, https://doi.org/10.3390/antiox9030250.

6. Kumar, M.; Nagpal, R.; Verma, V.; Kumar, A.; Kaur, N.; Hemalatha, R.; Gautam, S.K.; Singh, B. Probiotic metabolites as epigenetic targets in the prevention of colon cancer. Nutr. Rev. 2013, 71, 23-34, https://doi.org/10.1111/j.1753-4887.2012.00542.x.

7. Kareem, K.Y.; Hooi Ling, F.; Teck Chwen, L.; Foong, O.M.; Asmara, S.A. Inhibitory activity of postbiotic produced by strains of Lactobacillus plantarum using reconstituted media supplemented with inulin. Gut Pathog 2014, 6, 23, https://doi.org/10.1186/1757-4749-6-23.

8. Gao, J.; Li, Y.; Wan, Y.; Hu, T.; Liu, L.; Yang, S.; Gong, Z.; Zeng, Q.; Wei, Y.; Yang, W.; Zeng, Z.; He, X.; Huang, S.-H.; Cao, H. A Novel Postbiotic From Lactobacillus rhamnosus GG With a Beneficial Effect on Intestinal Barrier Function. Front. Microbiol. 2019, 10, 477, https://doi.org/10.3389/fmicb.2019.00477.

9. Howarth, G.; Wang, S.H. Role of endogenous microbiota, probiotics and their biological products in human health. Nutrients 2013, 5, 58-81, https://doi.org/10.3390/nu5010058.

10. Cremon, C.; Barbaro, M.R.; Ventura, M.; Barbara, G. Pre- and probiotic overview. Cur Opin Pharmacol 2018, 43, 87-92, https://doi.org/10.1016/j.coph.2018.08.010.

11. Kareem, K.Y.; Loh, T.C.; Foo, H.L.; Asmara, S.A.; Akit, H. Influence of postbiotic RG14 and inulin combination on cecal microbiota, organic acid concentration, and cytokine expression in broiler chickens. Poult Sci 2017, 96, 966-975, https://doi.org/10.3382/ps/pew362.

12. Konstantinov, S.; Kuipers, E.; Peppelenbosch, M. Functional genomic analyses of the gut microbiota for CRC screening. Nat Rev Gastroenterol Hepatol 2013, 10, 741-745, https://doi.org/10.1038/nrgastro.2013.178.

13. Dadi, T.H.; Vahjen, W.; Zentek, J.; Melzig, M.F.; Granica, S.; Piwowarski, J.P. Lythrum salicaria, L. Herb and gut microbiota of healthy post-weaning piglets. Focus on prebiotic properties and formation of postbiotic metabolites in ex vivo cultures. $J$ Ethnopharmacol 2020, 261, 113073, https://doi.org/10.1016/j.jep.2020.113073.

14. Sugiharto, S. Role of nutraceuticals in gut health and growth performance of poultry. J Saudi Soc Agric Sci 2016, 15, 99-111, https://doi.org/10.1016/j.jssas.2014.06.001.

15. Zorzela, L.; Ardestani, S.K.; McFarland, L.V.; Vohra, S. Is there a role for modified probiotics as beneficial microbes: a systematic review of the literature. Benef Microbes 2017, 8, 739-754, https://doi.org/10.3920/BM2017.0032.

16. Arena, M.P.; Silvain, A.; Normanno, G.; Grieco, F.; Drider, D.; Spano, G.; Fiocco, D. Use of Lactobacillus plantarum Strains as a Bio-Control Strategy against Food-Borne Pathogenic Microorganisms. Front. Microbiol. 2016, 7, 464, https://doi.org/10.3389/fmicb.2016.00464.

17. Kuitunen, M.; Kukkonen, A,K.; Savilahti, E. Impact of Maternal Allergy and Use of Probiotics during Pregnancy on Breast Milk Cytokines and Food Antibodies and Development of Allergy in Children until 5 Years. Int Arch Allergy Immunol 2012, 159, 162-170, https://doi.org/10.1159/000336157.

18. Wu, X.; Teame, T.; Hao, Q.; Ding, Q.; Liu, H.; Ran, C.; Yang, Y.; Zhang, Y.; Zhou, Z.; Duan, M.; Zhang, Z. Use of a paraprobiotic and postbiotic feed supplement (HWFTM) improves the growth performance, composition and function of gut microbiota in hybrid sturgeon (Acipenser baerii x Acipenser schrenckii). Fish Shellfish Immunol. 2020, 104, 36-45, https://doi.org/10.1016/j.fsi.2020.05.054.

19. Kasra Kermanshahi, R. Goodarzi, L.; The Effect of Prebiotics on Production of Antimicrobial Compounds from Lactobacillus spp. Against Proteus mirabilis (ATCC 7002 and PTCC 1076). Iran J Food Sci Technol Res 2015, 11, 41-47, https://doi.org/10.22067/ifstrj.v11i1.45434.

20. Pérez-Sánchez, T.; Mora-Sánchez, B.; Vargas, A.; Balcázar, JL. Changes in intestinal microbiota and disease resistance following dietary postbiotic supplementation in rainbow trout (Oncorhynchus mykiss). Microb pathog 2020, 142, 104060, https://doi.org/10.1016/j.micpath.2020.104060.

21. Ford, A.C.; Harris, L.A.; Lacy, B.E.; Quigley, E.M.; Moayyedi, P. Systematic review with meta-analysis: the efficacy of prebiotics, probiotics, synbiotics and antibiotics in irritable bowel syndrome. Aliment pharmacol ther 2018, 48, 1044-1060, https://doi.org/10.1111/apt.15001.

22. Hayes, S.R.; Vargas, A.J. Probiotics for the prevention of pediatric antibiotic-associated diarrhea. Explore 2016, 12, 463-466, https://doi.org/10.1016/j.explore.2016.08.015.

23. Holanda, D.M.; Yiannikouris, A.; Kim, S.W. Investigation of the efficacy of a postbiotic yeast cell wall-based blend on newly-weaned pigs under a dietary challenge of multiple mycotoxins with emphasis on deoxynivalenol. Toxins 2020, 12, 504, https://doi.org/10.3390/toxins12080504.

24. Al-Sheraji, S.H.; Ismail, A.; Manap, M.Y.; Mustafa, S.; Yusof, R.M.; Hassan, F.A. Prebiotics as functional foods: A review. J funct foods 2013, 5, 1542-1553, https://doi.org/10.1016/j.jff.2013.08.009.

https://biointerfaceresearch.com/ 
25. Ooi, M.F.; Foo, H.L.; Loh, T.C.; Mohamad, R.; Rahim, R.A.; Ariff, A. A refined medium to enhance the antimicrobial activity of postbiotic produced by Lactiplantibacillus plantarum RS5. Sci. Rep. 2021, 11, 7617, https://doi.org/10.1038/s41598-021-87081-6.

26. Inglin, R.C.; Stevens, M.J.A.; Meile, L.; Lacroix, C.; Meile, L. High-throughput screening assays for antibacterial and antifungal activities of Lactobacillus species. J. Microbiol. Methods 2015, 114, 26-29, https://doi.org/10.1016/j.mimet.2015.04.011.

27. Patel, R.M.; Denning, P.W. Therapeutic use of prebiotics, probiotics, and postbiotics to prevent necrotizing enterocolitis: what is the current evidence? Clin Perinatol 2013, 40, 11-25, https://doi.org/10.1016/j.clp.2012.12.002.

28. Żółkiewicz, J.; Marzec, A.; Ruszczyński, M.; Feleszko, W. Postbiotics-A Step Beyond Pre-and Probiotics. Nutrients 2020, 12, 2189, https://doi.org/10.3390/nu12082189.

29. Izuddin, W.I.; Loh, T.C.; Samsudin, A.A.; Foo, H.L. In vitro study of postbiotics from Lactobacillus plantarum RG14 on rumen fermentation and microbial population. Revista Brasileira de Zootecnia 2018, 47, https://doi.org/10.1590/rbz4720170255.

30. Loh, T.C.; Choe, D.W.; Foo, H.L.; Sazili, A.Q.; Bejo, M.H. Effects of feeding different postbiotic metabolite combinations produced by Lactobacillus plantarumstrains on egg quality and production performance, faecal parameters and plasma cholesterol in laying hens. BMC Vet. Res. 2014, 10, 149, https://doi.org/10.1186/17466148-10-149.

31. Martens, E.C.; Kelly, A.G.; Tauzin, A.S.; Brumer, H. The devil lies in the details: how variations in polysaccharide fine-structure impact the physiology and evolution of gut microbes. J Molecul Biol 2014, 426, 3851-3865, https://doi.org/10.1016/j.jmb.2014.06.022.

32. Yordshahi, A.S.; Moradi, M.; Tajik, H.; Molaei, R. Design and preparation of antimicrobial meat wrapping nanopaper with bacterial cellulose and postbiotics of lactic acid bacteria. Int J Food Microbiol 2020, 321, 108561, https://doi.org/10.1016/j.ijfoodmicro.2020.108561.

33. Holscher, H.D.; Caporaso, J.G.; Hooda S.; Jennifer M.; Brulc, G.C.; Fahey, J.R.; Swanson, K.S. Fiber supplementation influences phylogenetic structure and functional capacity of the human intestinal microbiome: follow-up of a randomized controlled trial. Am J clin nutr 2015, 101, 55-64, https://doi.org/10.3945/ajcn.114.092064.

34. Oliver, L.; Heather, R.; Mary B.G.; Yimin, C. Health care provider's knowledge, perceptions, and use of

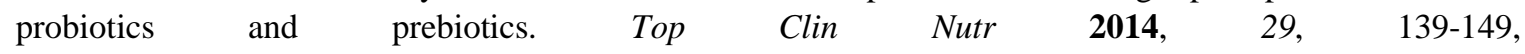
https://doi.org/10.1097/01.TIN.0000445898.98017.eb.

35. Pandey, K.R.; Naik, S.R.; Vakil, B.V. Probiotics, prebiotics and synbiotics- a review. J Food Sci Technol 2015, 52, 7577-7587, https://doi.org/10.1007/s13197-015-1921-1.

36. Ridwan, B. U.; Koning, C. J. M.; Besselink, M. G. H.; Timmerman, H. M.; Brouwer, E. C.; Verhoef, J.; Akkermans, L. M. A. Antimicrobial activity of a multispecies probiotic (Ecologic 641) against pathogens isolated from infected pancreatic necrosis. Letters Appl Microbiol 2008, 46, 61-67, https://doi.org/10.1111/j.1472-765X.2007.02260.x.

37. Moradi, M.; Kousheh, S. A.; Almasi, H.; Alizadeh, A.; Guimarães, J. T.; Y1lmaz, N.; Lotfi, A. Postbiotics produced by lactic acid bacteria: The next frontier in food safety. Com Rev Food Sci Food Saf 2020, 19, 33903415, https://doi.org/10.1111/1541-4337.12613.

38. Chen, C.C.; Lai, C.C.; Huang, H.L.; Huang, W.Y.; Toh, H.S.; Weng, T.C.; Chuang, Y.C.; Lu, Y.C.; Tang, H.J. Antimicrobial Activity of Lactobacillus Species Against Carbapenem-Resistant Enterobacteriaceae. Front Microb 2019, 10, 789, https://doi.org/10.3389/fmicb.2019.00789.

39. Tang, H.-J.; Hsieh, C.-F.; Chang, P.-C.; Chen, J.-J.; Lin, Y.-H.; Lai, C.-C.; Chao, C.-M.; Chuang, Y.-C. Clinical Significance of Community- and Healthcare-Acquired Carbapenem-Resistant Enterobacteriaceae Isolates. PLoS One 2016, 11, e0151897, https://doi.org/10.1371/journal.pone.0151897.

40. Majeed, M.; Majeed, S.; Nagabhushanam, K.; Mundkur, L.; Rajalakshmi, H.R.; Shah, K.; Beede, K. Novel Topical Application of a Postbiotic, LactoSporin, in Mild to Moderate Acne: A Randomized, Comparative Clinical Study to Evaluate its Efficacy, Tolerability and Safety. Cosmetics 2020, 7, 70, https://doi.org/10.3390/cosmetics7030070.

41. Shah, N.; Patel, A.; Ambalam, P.; Holst, O.; Ljungh, A.; Prajapati, J. Determination of an antimicrobial activity of Weissella confusa, Lactobacillus fermentum, and Lactobacillus plantarum against clinical pathogenic strains of Escherichia coli and Staphylococcus aureus in co-culture. Ann. Microbiol. 2016, 66, 1137-1143, https://doi.org/10.1007/s13213-016-1201-y.

42. Brown, D.F.J.; Wootton, M.; Howe, R.A. Antimicrobial susceptibility testing breakpoints and methods from BSAC to EUCAST. J. Antimicrob. Chemother. 2016, 71, 3-5, https://doi.org/10.1093/jac/dkv287.

43. Tokatli, M.; Gulgor, G.; Bagder Elmaci, S.; Arslankoz İsleyen, N.; Özçelik, F. In vitro properties of potential probiotic indigenous lactic acid bacteria originating from traditional pickles. Biomed Res Int 2015, 315819, https://doi.org/10.1155/2015/315819. 
44. Tang, H.-J.; Lai, C.-C.; Chen, C.-C.; Zhang, C.-C.; Weng, T.-C.; Chiu, Y.-H.; Toh, H.-S.; Chiang, S.-R.; Yu, W.-L.; Ko, W.-C.; Chuang, Y.-C. Colistin-sparing regimens against Klebsiella pneumoniae carbapenemaseproducing K. pneumoniae isolates: Combination of tigecycline or doxycycline and gentamicin or amikacin. J. Microbiol. Immunol. Infect. 2019, 52, 273-281, https://doi.org/10.1016/j.jmii.2016.03.003.

45. Humam, A.M.; Loh, T.C.; Foo, H.L.; Samsudin, A.A.; Mustapha, N.M.; Zulkifli, I.; Izuddin, W.I. Effects of feeding different postbiotics produced by Lactobacillus plantarum on growth performance, carcass yield, intestinal morphology, gut microbiota composition, immune status, and growth gene expression in broilers under heat stress. Animals 2019, 9, 644, https://doi.org/10.3390/ani9090644.

46. Loh, T. C.; Thu, T. V.; Foo, H. L.; Bejo, M. H. Effects of different levels of metabolite combination produced by Lactobacillus plantarum on growth performance, diarrhoea, gut environment and digestibility of postweaning piglets. J Appl Animal Res 2013, 41, 200-207, https://doi.org/10.1080/09712119.2012.741046.

47. Jean, S.S.; Coombs, G.; Ling, T.; Balaji, V.; Rodrigues, C.; Mikamo, H. Epidemiology and antimicrobial susceptibility profiles of pathogens causing urinary tract infections in the Asia-Pacific region: results from the study for monitoring antimicrobial resistance trends (SMART), 2010-2013. Int J Antimicrob Agents 2016, 47, 328-334, https://doi.org/10.1016/j.ijantimicag.2016.01.008.

48. Ajuwon, K. M. Toward a better understanding of mechanisms of probiotics and prebiotics action in poultry species. J Appl Poult Res 2016, 25, 277-283, https://doi.org/10.3382/japr/pfv074.

49. Ebrahimi, M.; Sadeghi, A.; Rahimi, D.; Purabdolah, H.; Shahryari, S. Postbiotic and Anti-aflatoxigenic Capabilities of Lactobacillus kunkeei as the Potential Probiotic LAB Isolated from the Natural Honey. Probiotics and Antimicrobial Proteins 2021, 13, 343-355, https://doi.org/10.1007/s12602-020-09697-w.

50. Rodriguez-Bano, J.; Gutierrez-Gutierrez, B.; Machuca, I.; Pascual, A. Treatment of infections caused by extended-spectrum-beta-lactamase-, ampC-, and carbapenemase-producing Enterobacteriaceae. Clin Microb Rev 2018, 31, e00079-17, https://doi.org/10.1128/CMR.00079-17.

51. Păcularu-Burada, B.; Georgescu, L. A.; Vasile, M. A.; Rocha, J. M.; Bahrim, G. E. Selection of wild lactic acid bacteria strains as promoters of postbiotics in gluten-free sourdoughs. Microorganisms 2020, 8, 643. https://doi.org/10.3390/microorganisms8050643.

52. Kumar, M.; Dhaka, P.; Vijay, D.; Vergis, J.; Mohan, V.; Kumar, A.; Kurkure, N.V.; Barbuddhe, S.B.; Malik, S.V.S.; Rawool, D.B. Antimicrobial effects of Lactobacillus plantarum and Lactobacillus acidophilus against multidrug-resistant enteroaggregative Escherichia coli. Int. J. Antimicrob. Agents 2016, 48, 265-270, https://doi.org/10.1016/j.ijantimicag.2016.05.014.

53. Teame, T.; Wang, A.; Xie, M.; Zhang, Z.; Yang, Y.; Ding, Q.; Gao, C.; Olsen, R.E.; Ran, C.; Zhou, Z. Paraprobiotics and Postbiotics of Probiotic Lactobacilli, Their Positive Effects on the Host and Action Mechanisms: A Review. Front nutr 2020, 7, 570344, https://doi.org/10.3389/fnut.2020.570344.

54. Kang, M. S.; Lim, H. S.; Oh, J. S.; Lim, Y. J.; Wuertz-Kozak, K.; Harro, J. M.; Achermann, Y. Antimicrobial activity of Lactobacillus salivarius and Lactobacillus fermentum against Staphylococcus aureus. Pathog Dis 2017, 75, https://doi.org/10.1093/femspd/ftx009.

55. Mookiah, S.; Sieo, C. C.; Ramasamy, K.; Abdullah, N.; Ho, Y. W. Effects of dietary prebiotics, probiotic and synbiotics on performance, caecal bacterial populations and caecal fermentation concentrations of broiler chickens. J Sci of Food Agric 2014, 94, 341-348, https://doi.org/10.1002/jsfa.6365.

56. Georgieva, R.; Yocheva, L.; Tserovska, L.; Zhelezova, G.; Stefanova, N.; Atanasova, A.; Karaivanova, E. Antimicrobial activity and antibiotic susceptibility of Lactobacillus and Bifidobacterium spp. intended for use as starter and probiotic cultures. Biotechnol Biotechnol Equip 2015, 29, 84-91, https://doi.org/10.1080/13102818.2014.987450.

57. Cortés-Martín, A.; Selma, M. V.; Tomás-Barberán, F. A.; González-Sarrías, A.; Espín, J. C. Where to look into the puzzle of polyphenols and health? The postbiotics and gut microbiota associated with human metabotypes. Molecul Nutr Food Res 2020, 64, 1900952, https://doi.org/10.1002/mnfr.201900952.

58. Grimoud, J.; Durand, H.; Courtin, C.; Monsan, P.; Ouarné, F.; Theodorou, V.; Roques, C. In vitro screening of probiotic lactic acid bacteria and prebiotic glucooligosaccharides to select effective synbiotics. Anaerobe 2010, 16, 493-500, https://doi.org/10.1016/j.anaerobe.2010.07.005.

59. Stein, DR.; Allen, DT.; Perry, EB.; Bruner, JC.; Gates, KW.; Rehberger, T.; Mertz, K.; Jones, D.; Spicer, LJ. Effects of feeding propionicbacteria to dairy cows on milk yield, milk components, and reproduction. J Dairy Sci 2008, 9, 111-125, https://doi.org/10.3168/jds.S0022-0302(06)72074-4.

60. Rad, A.H.; Maleki, L.A.; Kafil, H.S.; Zavoshti, H.F.; Abbasi, A. Postbiotics as novel health-promoting ingredients in functional foods. Health Promot Perspect 2020, 10, 3-4, https://doi.org/10.15171/hpp.2020.02.

61. Prieto, M. L.; O'Sullivan, L.; Tan, S. P.; McLoughlin, P.; Hughes, H.; Gutierrez, M.; Gardiner, G. E. In vitro assessment of marine Bacillus for use as livestock probiotics. Mar Drugs 2014, 12, 2422-2445, https://doi.org/10.3390/md12052422.

62. Chuah, L.-O.; Foo, H.L.; Loh, T.C.; Mohammed Alitheen, N.B.; Yeap, S.K.; Abdul Mutalib, N.E.; Abdul Rahim, R.; Yusoff, K. Postbiotic metabolites produced by Lactobacillus plantarum strains exert selective 
cytotoxicity effects on cancer cells. BMC Complement. Altern. Med. 2019, 19, 114, https://doi.org/10.1186/s12906-019-2528-2.

63. Malagón-Rojas, J.N.; Mantziari, A.; Salminen, S.; Szajewska, H. Postbiotics for Preventing and Treating Common Infectious Diseases in Children: A Systematic Review. Nutrients 2020, 12, https://doi.org/10.3390/nu12020389.

64. Devi, S.M.; Halami, P.M. Genetic Variation of pln Loci Among Probiotic Lactobacillus plantarum Group Strains with Antioxidant and Cholesterol-Lowering Ability. Probiotics Antimicrob 2019, 11, 11-22, https://doi.org/10.1007/s12602-017-9336-0.

65. Koohestani, M.; Moradi, M.; Tajik, H.; Badali, A. Effects of cell-free supernatant of Lactobacillus acidophilus LA5 and Lactobacillus casei 431 against planktonic form and biofilm of Staphylococcus aureus. Vet Res forum 2018, 9, 301-306, https://doi.org/10.30466/vrf.2018.33086.

66. Carlsson, A. H.; Yakymenko, O.; Olivier, I.; Håkansson, F.; Postma, E.; Keita, Å. V.; Söderholm, J. D. Faecalibacterium prausnitzii supernatant improves intestinal barrier function in mice DSS colitis. Scan J gastroenterol 2013, 48, 1136-1144, https://doi.org/10.3109/00365521.2013.828773.

67. Rushdy, A.A.; Gomaa, E.Z. Antimicrobial compounds produced by probiotic Lactobacillus brevis isolated from dairy products. Ann Microb 2013, 63, 81-90, https://doi.org/10.1007/s13213-012-0447-2.

68. Muhialdin, B.J.; Hassan, Z.; Sadon, S.K. Antifungal Activity of Lactobacillus fermentum Te007, Pediococcus pentosaceus Te010, Lactobacillus pentosus G004, and L. paracasi D5 on Selected Foods. J Food Sci 2011, 76, M493-M499, https://doi.org/10.1111/j.1750-3841.2011.02292.x.

69. Tejero-Sariñena, S.; Barlow, J.; Costabile, A.; Gibson, G. R.; Rowland, I. In vitro evaluation of the antimicrobial activity of a range of probiotics against pathogens: evidence for the effects of organic acids. Anaerobe 2012, 18, 530-538, https://doi.org/10.1016/j.anaerobe.2012.08.004.

70. Maldonado, N.C.; de Ruiz, C.S.; Otero, M.C.; Sesma, F.; Nader-Macías, M. E. Lactic acid bacteria isolated from young calves-characterization and potential as probiotics. Res Vet sci 2012, 92, 342-349, https://doi.org/10.1016/j.rvsc.2011.03.017.

71. Ang, C.Y.; Sano, M.; Dan, S.; Leelakriangsak, M.; Lal, T.M. Postbiotics applications as infectious disease control agent in aquaculture. Biocontrol Sci 2020, 25, 1-7, https://doi.org/10.4265/bio.25.1.

72. Khorshidian, N.; Yousefi Asli, M.; Hosseini, H.; Shadnoush, M.; Mortazavian, A. M. Potential anticarcinogenic effects of lactic acid bacteria and probiotics in detoxification of process-induced food toxicants. Iran J Cancer Prevent 2016, 1-13, http://eprints.semums.ac.ir/id/eprint/908.

73. Giang, H.H.; Viet, T.Q.; Ogle, B.; Lindberg, J.E. Effects of different probiotic complexes of lactic acid bacteria on growth performance and gut environment of weaned piglets. Livestock Sci 2010, 133, 182-184, https://doi.org/10.1016/j.livsci.2010.06.059.

74. Doi, K.; Nishizaki, Y.; Kimura, H.; Kitahara, M.; Fujino, Y.; Ohmomo, S.; Ogata, S. Identification of thermo tolerant lactic acid bacteria isolated from silage prepared in the hot and humid climate of Southwestern Japan. Springerplus 2013, 2, 1-12, https://doi.org/10.1186/2193-1801-2-485.

75. Boricha, A. A.; Shekh, S. L.; Pithva, S. P.; Ambalam, P. S.; Vyas, B. R. M. In vitro evaluation of probiotic properties of Lactobacillus species of food and human origin. LWT-Food Sci Technol 2019, 106, 201-208, https://doi.org/10.1016/j.lwt.2019.02.021.

76. Monteagudo-Mera, A.; Rodríguez-Aparicio, L.; Rúa, J.; Martínez-Blanco, H.; Navasa, N.; García-Armesto, M.R.; Ferrero, M.Á. In vitro evaluation of physiological probiotic properties of different lactic acid bacteria strains of dairy and human origin. J Funct Foods 2012, 4, 531-541, https://doi.org/10.1016/j.jff.2012.02.014.

77. Vrzáčková, N.; Ruml, T.; Zelenka, J. Postbiotics, Metabolic Signaling, and Cancer. Molecules 2021, 26, 1528, https://doi.org/10.3390/molecules26061528.

78. Devi, S.M.; Archer, A.C.; Halami, P.M. Screening, Characterization and In Vitro Evaluation of Probiotic Properties Among Lactic Acid Bacteria Through Comparative Analysis. Probiotics Antimicrob 2015, 7, 181 192, https://doi.org/10.1007/s12602-015-9195-5.

79. Allameh, S.K.; Daud, H.; Yusoff, F.M.; Saad, C.R.; Ideris, A. Isolation, identification and characterization of Leuconostoc mesenteroides as a new probiotic from intestine of snakehead fish (Channa striatus). African J Biotechnol 2012, 11, 3810-3816, https://doi.org/10.5897/AJB11.1871.

80. Zapata, A. A.; Lara-Flores, M. Antimicrobial activities of lactic acid bacteria strains isolated from Nile Tilapia intestine (Oreochromis niloticus). J Biol Life Sci 2013, 4, 164-171, https://doi.org/10.5296/jbls.v4i1.2408.

81. Muñoz-Atienza, E.; Araújo, C.; Magadán, S.; Hernández, P.E.; Herranz, C.; Santos, Y.; Cintas, L.M. In vitro and in vivo evaluation of lactic acid bacteria of aquatic origin as probiotics for turbot (Scophthalmus maximus L) farming. Fish Shellfish Immunol 2014, 41, 570-580, https://doi.org/10.1016/j.fsi.2014.10.007.

82. Moreno Munoz, J. A.; Chenoll, E.; Casinos, B.; Bataller, E.; Ramón, D.; Genovés, S.; Rivero, M. Novel probiotic Bifidobacterium longum subsp. infantis CECT 7210 strain active against rotavirus infections. Appl Environ Microbiol 2011, 77, 8775-8783, https://doi.org/10.1128/AEM.05548-11. 
83. Sarkono, S.; Faturrahman F.; Sofyan Y. Isolation and identification of lactic acid bacteria from abalone (Haliotis asinina) as a potential candidate of probiotic. Nus Biosci 2010, 2, 2087-3940, https://doi.org/10.13057/nusbiosci/n020106.

84. Karovičová, J.; Kohajdová, Z. Lactic acid fermentation of various vegetable juices. Acta Aliment 2005, 34, 237-246, https://doi.org/10.1556/aalim.34.2005.3.5.

85. Jama, Y.H.; Varadaraj, M. Antibacterial effect of plantaricin LP84 on foodborne pathogenic bacteria occurring as contaminants during idli batter fermentation. World J Microb Biotechnol 1999, 15, 27-32, https://doi.org/10.1023/A:1008887201516.

86. Mantziari, A.; Salminen, S.; Szajewska, H.; Malagón-Rojas, J. N. Postbiotics against pathogens commonly involved in pediatric infectious diseases. Microorganisms 2020, 8, 1510, https://doi.org/10.3390/microorganisms8101510.

87. Lammers, K.M.; Vergopoulos, A.; Babel, N.; Gionchetti, P.; Rizzello, F.; Morselli, C.; Caramelli, E.; Fiorentino, M.; d'Errico, A.; Volk, H.-D.; Campieri, M. Probiotic Therapy in the Prevention of Pouchitis Onset: Decreased Interleukin-1 $\beta$, Interleukin-8, and Interferon- $\gamma$ Gene Expression. Inflamm. Bowel Dis. 2005, 11, 447-454, https://doi.org/10.1097/01.mpa.0000160302.40931.7b.

88. Kato-Mori, Y.; Orihashi, T.; Kanai, Y.; Sato, M.; Sera, K.; Hagiwara, K. Fermentation metabolites from Lactobacillus gasseri and Propionibacterium freudenreichii exert bacteriocidal effects in mice. J Med Food 2010, 13, 1460-1467, https://doi.org/10.1089/jmf.2010.1137.

89. Fong, W.; Li, Q.; Yu, J. Gut microbiota modulation: a novel strategy for prevention and treatment of colorectal cancer. Oncogene 2020, 39, 4925-4943, https://doi.org/10.1038/s41388-020-1341-1.

90. Ratajczak, C.; Duez, C.; Grangette, C.; Pochard, P.; Tonnel, A. B.; Pestel, J. Impact of lactic acid bacteria on dendritic cells from allergic patients in an experimental model of intestinal epithelium. J Biomed Biotechnol 2007, 2007, 71921, https://doi.org/10.1155/2007/71921.

91. Kießling, G.; Schneider, J.; Jahreis, G. Long-term consumption of fermented dairy products over 6 months increases HDL cholesterol. Eur. J. Clin. Nutr. 2002, 56, 843-849, https://doi.org/10.1038/sj.ejcn.1601399.

92. Ishikawa, H.; Akedo, I.; Otani, T.; Suzuki, T.; Nakamura, T.; Takeyama, I.; Kakizoe, T. Randomized trial of dietary fiber and Lactobacillus casei administration for prevention of colorectal tumors. Int J Cancer 2005, 116, 762-767, https://doi.org/10.1002/ijc.21115.

93. Ahmad Rather, I.; Seo, B.; Rejish Kumar, V.J.; Choi, U.H.; Choi, K.H.; Lim, J.H.; Park, Y.H. Isolation and characterization of a proteinaceous antifungal compound from L actobacillus plantarum YML 007 and its application as a food preservative. Letters Appl Microbiol 2013, 57, 69-76, https://doi.org/10.1111/lam.12077.

94. Torino, M.I.; Font de Valdez, G.; Mozzi, F. Biopolymers from lactic acid bacteria. Novel applications in foods and beverages. Front Microbiol 2015, 6, 834, https://doi.org/10.3389/fmicb.2015.00834.

95. Bosch, M.; Nart, J.; Audivert, S.; Bonachera, M.A.; Alemany, A.S.; Fuentes, M.C.; Cuné, J. Isolation and characterization of probiotic strains for improving oral health. Arch Oral Biol 2012, 57, 539-549, https://doi.org/10.1016/j.archoralbio.2011.10.006.

96. Aguilar-Toalá, J.E.; Garcia-Varela, R.; Garcia, H.S.; Mata-Haro, V.; González-Córdova, A.F.; VallejoCordoba, B.; Hernández-Mendoza, A. Postbiotics: An evolving term within the functional foods field. Trends Food Sci Technol 2018, 75, 105-114, https://doi.org/10.1016/j.tifs.2018.03.009.

97. Wegh, C. A.; Geerlings, S.Y.; Knol, J.; Roeselers, G.; Belzer, C. Postbiotics and their potential applications in early life nutrition and beyond. Int J Mol Sci 2019, 20, 4673, https://doi.org/10.3390/ijms20194673.

98. Reynés, B.; Palou, M.; Rodríguez, A.M.; Palou, A. Regulation of adaptive thermogenesis and browning by prebiotics and postbiotics. Front physiol 2019, 9, 1908, https://doi.org/10.3389/fphys.2018.01908.

99. Thu, T.V.; Loh, T.C.; Foo, H.L.; Yaakub, H.; Bejo, M.H. Effects of liquid metabolite combinations produced by Lactobacillus plantarum on growth performance, faeces characteristics, intestinal morphology and diarrhoea incidence in postweaning piglets. Trop. Anim. Health Prod. 2011, 43, https://doi.org/10.1007/s11250-010-9655-6.

100.Cicenia, A.; Scirocco, A.; Carabotti, M.; Pallotta, L.; Marignani, M.; Severi, C. Postbiotic activities of

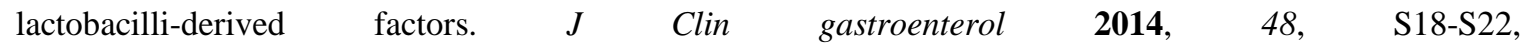
https://doi.org/10.1097/MCG.0000000000000231.

101.Brodmann, T.; Endo, A.; Gueimonde, M.; Vinderola, G.; Kneifel, W.; de Vos, W.M.; Gómez-Gallego, C. Safety of Novel Microbes for Human Consumption: Practical Examples of Assessment in the European Union. Front Microbiol 2017, 8, 1725, https://doi.org/10.3389/fmicb.2017.01725.

102. Salminen, S.; Collado, M.C.; Endo, A.; Hill, C.; Lebeer, S.; Quigley, E.M.M.; Sanders, M.E.; Shamir, R.; Swann, J.R.; Szajewska, H.; Vinderola, G. The International Scientific Association of Probiotics and Prebiotics (ISAPP) consensus statement on the definition and scope of postbiotics. Nature Reviews Gastroenterology \& Hepatology 2021, https://doi.org/10.1038/s41575-021-00440-6. 
103. Abdolhosseinzadeh, E.; Dehnad, A.R.; Pourjafar, H.; Homayouni, A.; Ansari, F. The production of probiotic scallion yogurt: viability of Lactobacillus acidophilus freely and microencapsulated in the product. Carpath J Food Sci Technol 2018, 10(3), 72-80.

104. Ghorbani-Choboghlo, H.; Zahraei-Salehi, T.; Ashrafi-Helan, J.; Yahyaraeyat, R.; Pourjafar, H.; Nikaein, D.; Balal, A.; Khosravi, A.R. Microencapsulation of Saccharomyces cerevisiae and its evaluation to protect in simulated gastric conditions. Iran J Microbiol 2015, 7(6), 338. 